\title{
Acoustic Efficiency of Azimuthal Modes in Jet Noise Using Chevron Nozzles
}

Clifford A. Brown and James Bridges

Glenn Research Center, Cleveland, Ohio 


\section{NASA STI Program . . . in Profile}

Since its founding, NASA has been dedicated to the advancement of aeronautics and space science. The NASA Scientific and Technical Information (STI) program plays a key part in helping NASA maintain this important role.

The NASA STI Program operates under the auspices of the Agency Chief Information Officer. It collects, organizes, provides for archiving, and disseminates NASA's STI. The NASA STI program provides access to the NASA Aeronautics and Space Database and its public interface, the NASA Technical Reports Server, thus providing one of the largest collections of aeronautical and space science STI in the world. Results are published in both non-NASA channels and by NASA in the NASA STI Report Series, which includes the following report types:

- TECHNICAL PUBLICATION. Reports of completed research or a major significant phase of research that present the results of NASA programs and include extensive data or theoretical analysis. Includes compilations of significant scientific and technical data and information deemed to be of continuing reference value. NASA counterpart of peer-reviewed formal professional papers but has less stringent limitations on manuscript length and extent of graphic presentations.

- TECHNICAL MEMORANDUM. Scientific and technical findings that are preliminary or of specialized interest, e.g., quick release reports, working papers, and bibliographies that contain minimal annotation. Does not contain extensive analysis.

- CONTRACTOR REPORT. Scientific and technical findings by NASA-sponsored contractors and grantees.
- CONFERENCE PUBLICATION. Collected papers from scientific and technical conferences, symposia, seminars, or other meetings sponsored or cosponsored by NASA.

- SPECIAL PUBLICATION. Scientific, technical, or historical information from NASA programs, projects, and missions, often concerned with subjects having substantial public interest.

- TECHNICAL TRANSLATION. Englishlanguage translations of foreign scientific and technical material pertinent to NASA's mission.

Specialized services also include creating custom thesauri, building customized databases, organizing and publishing research results.

For more information about the NASA STI program, see the following:

- Access the NASA STI program home page at http://www.sti.nasa.gov

- E-mail your question via the Internet to help@sti.nasa.gov

- Fax your question to the NASA STI Help Desk at 301-621-0134

- Telephone the NASA STI Help Desk at 301-621-0390

- Write to:

NASA STI Help Desk

NASA Center for AeroSpace Information 7115 Standard Drive Hanover, MD 21076-1320 
NASA/TM-2006-214364

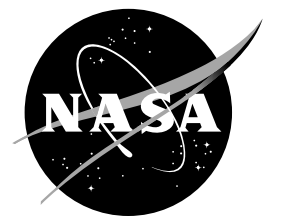

\section{Acoustic Efficiency of Azimuthal Modes in Jet Noise Using Chevron Nozzles}

Clifford A. Brown and James Bridges

Glenn Research Center, Cleveland, Ohio

Prepared for the

12th Aeroacoustics Conference

cosponsored by the American Institute of Aeronautics and Astronautics and the Confederation of European Aerospace Societies

Cambridge, Massachusetts, May 8-10, 2006

National Aeronautics and

Space Administration

Glenn Research Center

Cleveland, Ohio 44135 
Level of Review: This material has been technically reviewed by technical management.

Available from

NASA Center for Aerospace Information

7115 Standard Drive

Hanover, MD 21076-1320
National Technical Information Service 5285 Port Royal Road Springfield, VA 22161

Available electronically at http://gltrs.grc.nasa.gov 


\title{
Acoustic Efficiency of Azimuthal Modes in Jet Noise Using Chevron Nozzles
}

\author{
Clifford A. Brown and James Bridges \\ National Aeronautics and Space Administration \\ Glenn Research Center \\ Cleveland, Ohio 44135
}

\begin{abstract}
The link between azimuthal modes in jet turbulence and in the acoustic sound field has been examined in cold, round jets. Chevron nozzles, however, impart an azimuthal structure on the jet with a shape dependent on the number, length and penetration angle of the chevrons. Two particular chevron nozzles, with 3 and 4 primary chevrons respectively, and a round baseline nozzle are compared at both cold and hot jet conditions to determine how chevrons impact the modal structure of the flow and how that change relates to the sound field. The results show that, although the chevrons have a large impact on the azimuthal shape of the mean axial velocity, the impact of chevrons on the azimuthal structure of the fluctuating axial velocity is small at the cold jet condition and smaller still at the hot jet condition. This is supported by results in the azimuthal structure of the sound field, which also shows little difference in between the two chevron nozzles and the baseline nozzle in the distribution of energy across the azimuthal modes measured.
\end{abstract}

\section{Motivation}

Historically, most concepts envisioned to reduce jet noise have not reduced the total acoustic power of the jet. Rather, these designs, if they do not increase the total noise, simply translate the acoustic power from one frequency to another, more advantageous, frequency or from one observer angle to another, less critical, observer angle. This illustrates the robust nature of noise generation by a jet and explains why the greatest success in noise reduction has been achieved by lowering the jet velocity while maintaining thrust by increased bypass ratio. Several studies have considered the production of jet noise using a modal decomposition of jet and its corresponding sound field. Michalke and Fuchs addressed the problem theoretically by expanding the source term from Lighthill's equation, cast in cylindrical coordinates, in azimuthal angle as a Fourier series. The result showed that only the lowest order terms, corresponding to the lowest order azimuthal modes, are efficient producers of sound. Michalke and Fuchs also measured pressure correlations in the jet to support their theoretical finding and showed that the lowest terms dominate the turbulent source quantity in a low speed jet (ref. 1). Experimentally, by computing the Fourier coefficients of fluctuating jet pressure measurements near the jet shear layer, Armstrong et al. showed that the lowest order modes dominate in the near field of the jet (ref. 2). While these results established the modal energy distribution in the near field turbulence, Juve et al. measured the modal content in the acoustic far field at three observation angles and showed the dominance of the lowest three azimuthal modes in this region (ref. 3). These experiments were all conducted on cold, round jets. Do these results hold for a non-round or a hot jet?

Research shows that chevron nozzles reduce low frequency noise at aft angles while increasing high frequency noise at broadside angles relative to the jet (ref. 4). However, it will be shown that chevron nozzles also force flow energy into higher azimuthal modes than typically found, in significant strength, in a round nozzle. Examining both the near and far field azimuthal components from different chevron nozzles allows further analysis of the correlation between turbulent fluctuations and radiated sound as a function of azimuthal mode. If, for example, a chevron nozzle enhances the flow energy in mode $\mathrm{m}=3$, does that lead to a corresponding increase in mode $m=3$ sound radiated to the far field or is $m=3$ simply incapable of producing significantly more far field sound regardless of the flow energy it contains? Using 
particle image velocimetry (PIV) for near field flow measurements and an array of microphones located on a series of rings for mid-field acoustic measurements, this research further investigates the relationship between flow energy and sound production, using azimuthal modes, in round and chevron nozzles at hot and cold jet conditions.

\section{Test Hardware}

\section{Jet Rig}

Tests were conducted on the Small Hot Jet Acoustic Rig (SHJAR) located in the AeroAcoustic Propulsion Laboratory (AAPL) at the NASA Glenn Research Center. The SHJAR uses remotely located compressors and a hydrogen burning combustor to provide heated air to single-flow nozzles at temperatures up to $1300^{\circ} \mathrm{F}$ and at pressures up to $150 \mathrm{psi}$. Noise generated by flow through piping and control valves is removed using a baffled muffler and the flow is conditioned using screens to create clean and quiet conditions at the nozzle exit. Acoustic data repeatability has been determined to be within $0.5 \mathrm{~dB}$ in one-third octave bands at all frequencies. The SHJAR is housed in the AAPL, a $60 \mathrm{ft}$ radius geodesic dome lined with sound absorbing wedges creating an anechoic environment above $200 \mathrm{~Hz}$. Further details about the SHJAR including documentation of rig noise, background noise, nozzle boundary layer measurements, baseline data set, and comparisons to other jet rigs may be found in references 5 and 6 .

\section{Models}

A series of chevron nozzle extensions were developed to parametrically explore the impact of different chevron parameters (chevron number, penetration angle, and length) on jet noise. The design methodology for this nozzle set is described in reference 4 . Nozzles tested range from a round baseline nozzle to a 10 -chevron configuration with chevron penetration angles from $0^{\circ}$ to $18.2^{\circ}$. All nozzles in this set had a 2-in. exit diameter $\left(D_{j}\right)$. During the test, flow and acoustic data was not collected for all nozzles at all conditions. Two chevron nozzles, which produce three and four lobed flow cross section, and one round baseline nozzle are presented here. Pictures of these nozzles are shown in figure 1 . The first chevron nozzle, designated FCC001, has three primary chevrons and a $5^{\circ}$ penetration angle. The second chevron nozzle, designated FCC002, has four primary chevrons and a $5^{\circ}$ penetration angle. The round baseline nozzle is designated SMC000. Both chevron nozzle incorporated serrated ("fractal") edges, a feature which is not considered of primary importance here.

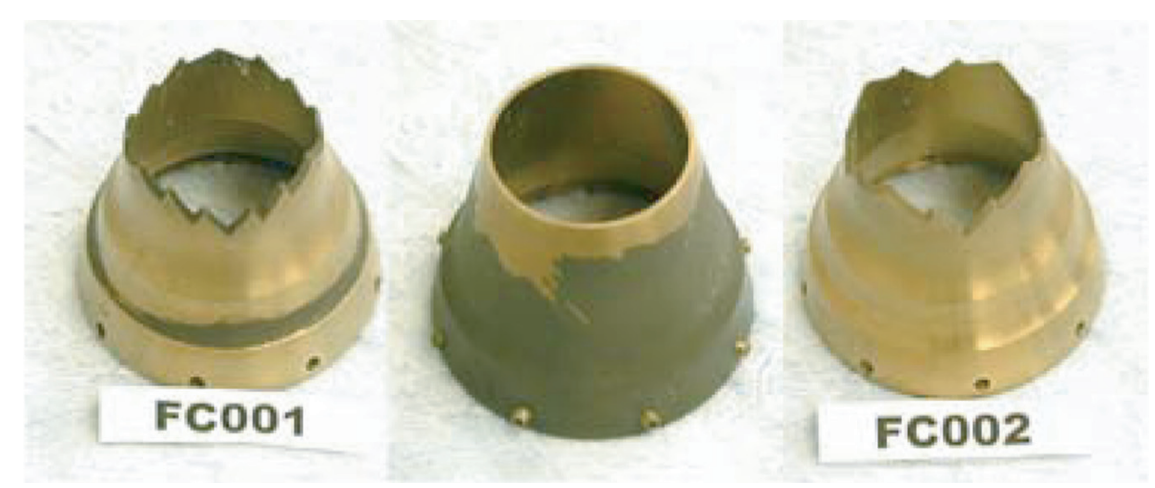

Figure 1.-The three nozzles presented in this paper are FCC001 (left), SMC000 baseline (middle), and FCC002 (right). FCC001 has three primary chevrons with smaller chevrons cut into the edges and FCC002 has four primary chevrons also with small chevrons cut into the edges. 


\section{Data Acquisition and Processing}

\section{Flow Measurements}

The three components of jet velocity (u, v, w) were measured using Stereoscopic Particle Image Velocimetry (PIV), in the cross-stream plane, at 12 locations along the jet axis. The jet flow was seeded with alumina particles $(\sim 0.5 \mu \mathrm{m}$ diameter $)$ injected upstream of the combustor. The ambient air surrounding the nozzle was seeded using a commercial fog machine (oil drop $\sim 0.2 \mu \mathrm{m}$ diameter). Light was supplied by dual-head Nd: YAG laser. Two 2048 by 2048 pixel cross-correlation cameras, ultimately giving a 215 by $160 \mathrm{~mm}$ field of view, were placed an angle to the light sheet to capture the three velocity components $(\mathrm{u}, \mathrm{v}, \mathrm{w})$. A total of 200 image pairs were recorded at each point. Data processing, using code developed at NASA (ref. 7), was used to combine the images from each camera to create the instantaneous three-dimensional velocity maps yielding a final resolution of $1.58 \mathrm{~mm}\left(0.03 D_{j}\right)$ in the cross-stream plane and $1.17 \mathrm{~mm}\left(0.02 D_{j}\right)$ in the stream-wise plane. Outlying vectors were discarded using both hard velocity limits and Chauvenet's criterion for data clean up. Further details on the PIV setup and procedure for calculating the instantaneous velocity maps are available in reference 8 .

Once the instantaneous velocity maps are obtained, turbulence statistics and modal energy are calculated. First, time averaged mean $(\bar{u}, \bar{v}, \bar{w})$ and fluctuating $\left(u^{\prime}=u-\bar{u}, v^{\prime}=v-\bar{v}, w^{\prime}=w-\bar{w}\right)$ components of the three velocity vectors are calculated for each instantaneous resolved vector. Next, to facilitate calculating azimuthal mode energy, the fluctuating axial velocity (w') is mapped, using bilinear interpolation, from the native Cartesian coordinate system to a polar coordinate system, placing 125 velocity vectors (equally spaced in azimuthal angle with $\Delta \Theta=0.05$ radians $\approx 28.6^{\circ}$ ) on 64 constant radius rings (from 1 to $65 \mathrm{~mm}$ radius). Azimuthal modes were calculated using only the fluctuating axial velocity (w'), which as the largest velocity component approximates the turbulent kinetic energy. The power in each azimuthal mode is determined by computing the Fourier transform, in azimuthal angle at each radius, for each of the instantaneous velocity maps and ensemble averaging the results. This process is repeated for each measured plane.

\section{Acoustic Measurements}

Acoustic modes were measured using microphones placed on rings around the jet axis. The array, which was originally designed and used as a three-dimensional phased array, contained 80 microphones (Bruel \& Kjaer 0.25 in. type 4939) on 15 rings. The microphones were evenly spaced in azimuthal angle on each ring with the first microphone offset $18^{\circ}$ from the first microphone on the previous ring (fig. 2). The first 10 rings, nearest to the nozzle exit, had six microphones each while the remaining rings had four microphones each (table I). The ring radius started at $35 \mathrm{in}$. near the nozzle exit and expanded to 50 in. at the downstream most ring. This put the array in the jet mid-field $\left(50 D_{j}\right.$ was determined to be far field for this jet (ref. 6)). Data was recorded simultaneously on all channels, continuously sampled at $50 \mathrm{kHz}$ (20 kHz bandwidth) for $20 \mathrm{sec}$ using a DataMAX Instrumentation Recorder from R.C. Electronics. Bruel \& Kjaer Nexus (type 2690) amplifiers provided signal conditioning and amplification. Jet and ambient conditions were recorded using the facility ESCORT computer system.

TABLE I.-SETUP INFORMATION FOR THE

MICROPHONE ARRAY USED TO ACQUIRE

THE MODAL ACOUSTIC MEASUREMENTS.

[Only the rings used to acquire the data

presented are shown in the table.]

\begin{tabular}{|c|c|c|c|c|}
\hline Ring & $\mathrm{X}$, & Radius, & $\mathrm{N}_{\text {mics }}$ & $\Theta_{1}$, \\
\hline 3 & 0.00 & 35.0 & 6 & 36 \\
\hline 4 & 4.00 & 35.75 & 6 & 54 \\
\hline 9 & 24.75 & 39.5 & 6 & 24 \\
\hline 10 & 31.25 & 40.75 & 6 & 42 \\
\hline
\end{tabular}




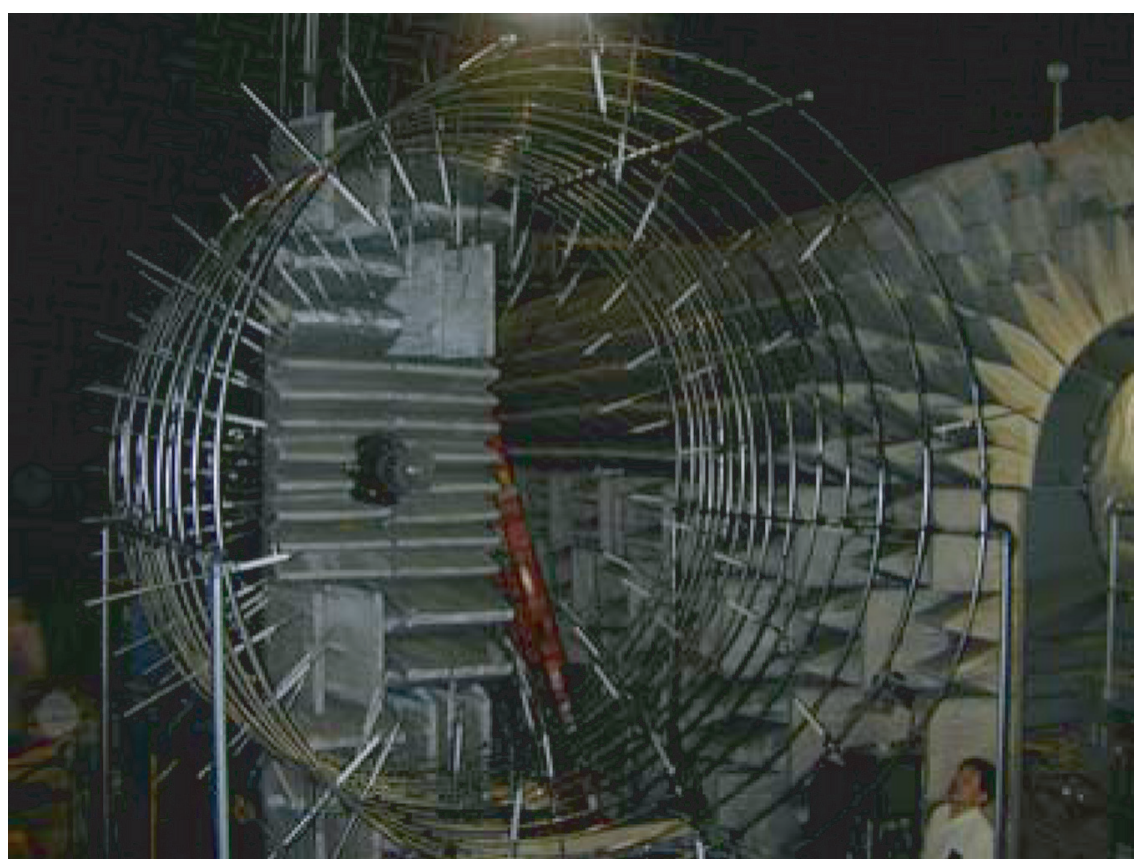

Figure 2.-Microphone ring array.
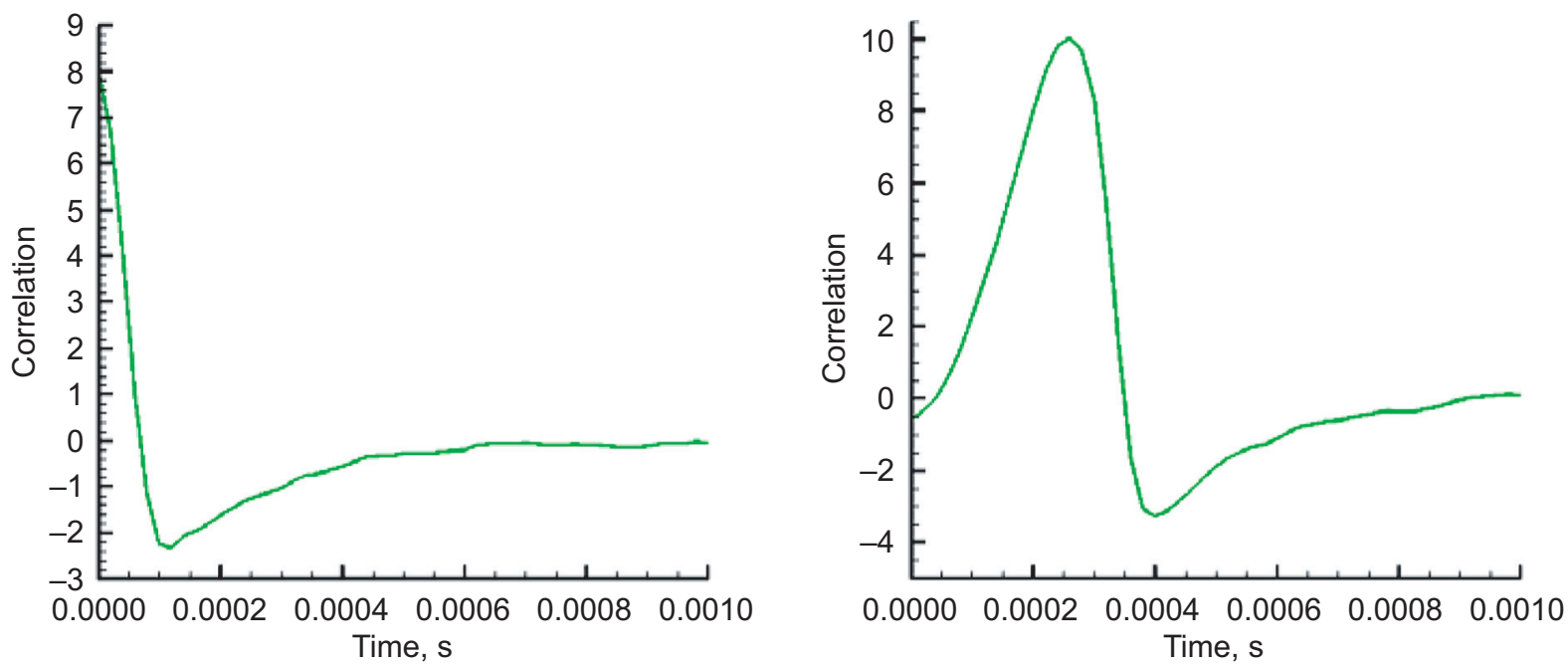

Figure 3.-Cross correlations used to determine the time offset between two rings near $90^{\circ}$ relative to the jet axis (left) and near $125^{\circ}$ relative to the jet axis (right) at an acoustic Mach 0.9 , cold jet condition using the round baseline nozzle (SMC000). The axial spacing of the rings grows downstream leading to the increase in time offset at these locations.

If data from only one ring is used to calculate the modal content of the sound field, the results will be limited to the lower order azimuthal modes $(0,1$, and 2$)$. Therefore, to determine the modal content of the sound field in the higher modes of interest, it is necessary to combine data from multiple rings. The azimuthal angle offset and close axial spacing between rings assists this combination, but using data from multiple rings does reduce the ability of the array to resolve high frequencies. To combine data from multiple rings, a cross correlation between microphones, at the nearest possible azimuthal angle on different rings, is used to get a time offset between the rings (fig. 3). This accounts for the different propagation lengths from the source to the microphones at different axial and radial positions. The 

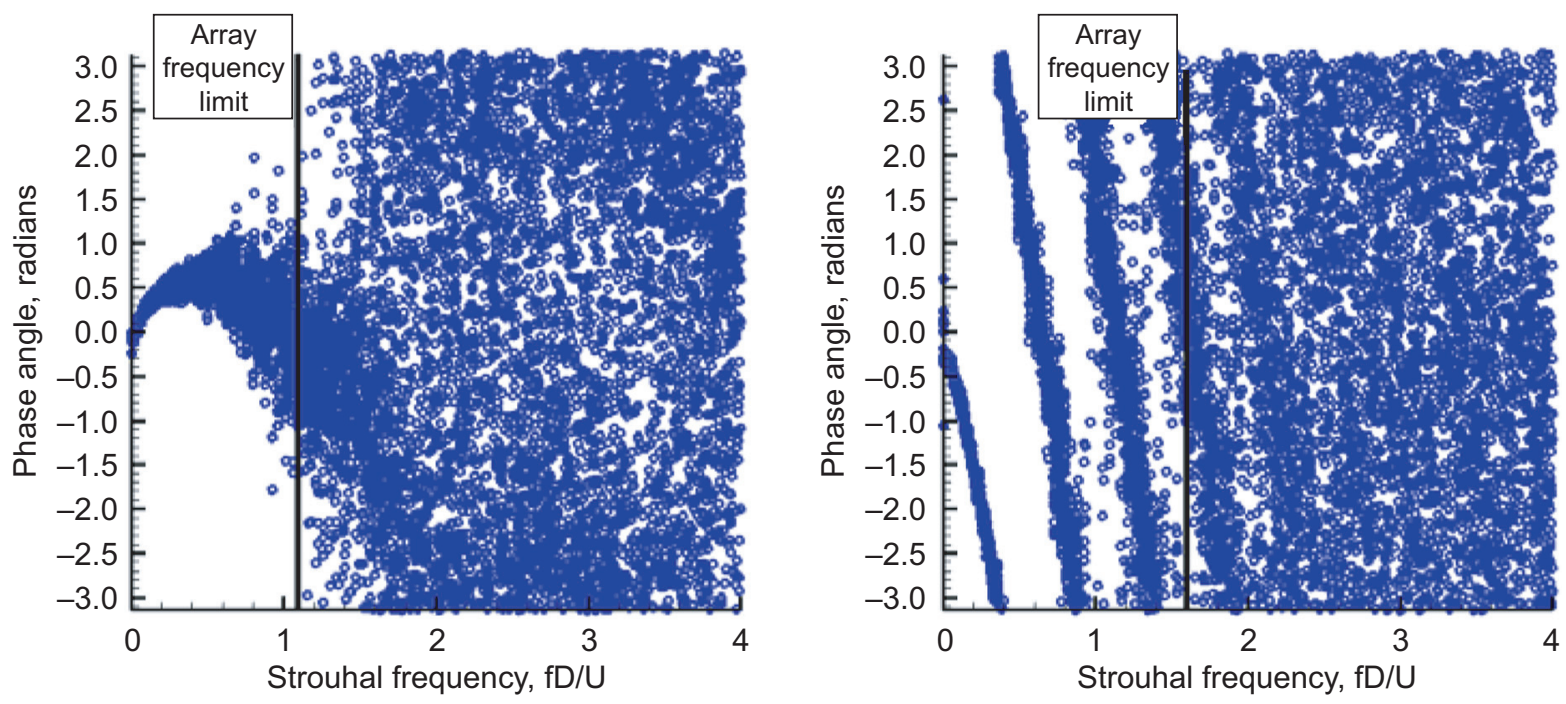

Figure 4.-Cross spectrum phase angle from microphones located on rings near $90^{\circ}$ relative to the jet axis (left) and at approximately $125^{\circ}$ relative to the jet axis (right) for the round baseline nozzle (SMC000) and at an acoustic Mach number 0.9, cold jet condition. The high frequency limit of the array is determined at the point where the phase angle appears to become random. At $90^{\circ}$ (left) this change occurs around Strouhal frequency 1.2 and at $125^{\circ}$ (right) it occurs near Strouhal frequency 1.6.

frequency limit of the array is determined at the frequency where the cross spectrum phase angle, between microphones on the different rings, becomes random, as opposed to varying smoothly. In order to resolve at least Strouhal frequency 1, only data from two rings could be combined, limiting the highest azimuthal mode that could be resolved to $\mathrm{m}=5$. Figure 4 shows cross spectrum phase angle plots for two ring locations, one near $90^{\circ}$ and the other near $125^{\circ}$ relative to the jet axis, for a cold, acoustic Mach 0.9 jet condition. The $90^{\circ}$ plot shows a Strouhal frequency limit of 1.2 while the $125^{\circ}$ data shows a Strouhal frequency limit of 1.6.

Once the data from the rings is combined, the azimuthal modal distribution of the acoustic field is calculated. First, direct integration of the Fourier series, in azimuthal angle, at each point in time is calculated. The direct integration method is necessary due to the uneven spacing of the microphones in azimuthal angle. The results, which are time series data divided into spatial modes, are then processed using a standard fast Fourier transform routine in time. The result is modal spectra in space and time.

\section{Results}

\section{Flow Analysis}

Steroscopic Particle Image Velocimetry (PIV) was employed to measure the three velocity components in a cold, acoustic Mach $M_{a}=0.9$ jet using the SMC000, FCC001 and FCC002 nozzles and in a hot $\mathrm{M}_{\mathrm{a}}=0.9$, temperature ratio $T_{s, j} / T_{a}=2.70$ jet using the $\mathrm{SMC} 000$ and $\mathrm{FCC} 001$. The time averaged axial velocity at 6 cross sectional planes for each case are shown in figure 5 . The three lobes in the FCC001 plume and the four lobes in the FCC002 plume, created by the number of primary chevrons in each case, is clearly observable in the mean flow data. Note the distance of 1 to 2 jet diameters $\left(D_{j}\right)$ required for the lobes to fully develop as it takes some distance for the vorticies generated by the chevrons to form and grow. Once developed, however, clear differences in the mean flow data are observed at location $x / D_{j}=2.0$ and, although diminished by further mixing, exist out to the final plane at $x / D_{j}=15.0$ where the plume shape from the chevron nozzles approaches the baseline. The addition of heat to the FCC001 nozzle cases reduces the size and definition of the lobes, creating flow field that is similar to the 


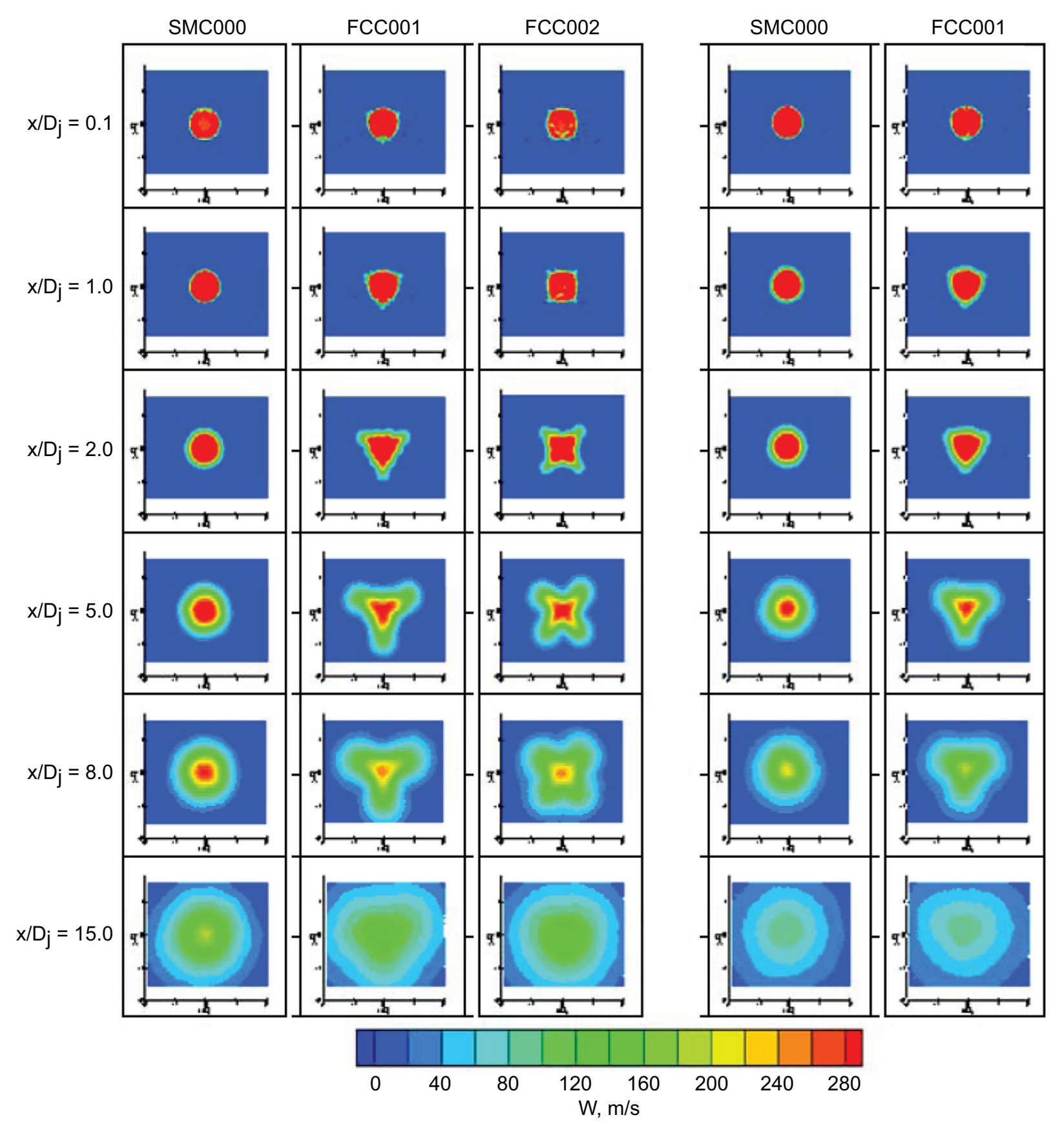

Figure 5.-Mean axial velocity at 6 cross stream planes for the SMC000, FCC001, and FCC002 nozzles at a acoustic Mach 0.9, cold jet condition (left) and for the SMC000 and FCC001 nozzles at an acoustic Mach 0.9, temperature ratio $\mathrm{T}_{\mathrm{S}}, \mathrm{j} / \mathrm{T}_{\mathrm{a}}=2.70$ jet condition (right).

round SMC000 nozzle case at the downstream planes. While this examination of the axial mean flow gives an idea of the plume shape, the primary interest is in the behavior of the axial velocity fluctuations, which may differ from the behavior of the mean flow.

The fluctuating component of axial velocity (w') was used to analyze the azimuthal modes in the jet plume. The results (fig. 6 for cold flow, fig. 7 for hot flow) show several things. First, data from the round baseline SMC000 nozzle shows qualitative agreement with linear stability theory. Each azimuthal mode (above mode $\mathrm{m}=0$, which is reduced by subtraction of the mean flow) saturates closer to the nozzle exit and at lower amplitude compared to the previous mode. Data from the chevron nozzles in the cold flow 

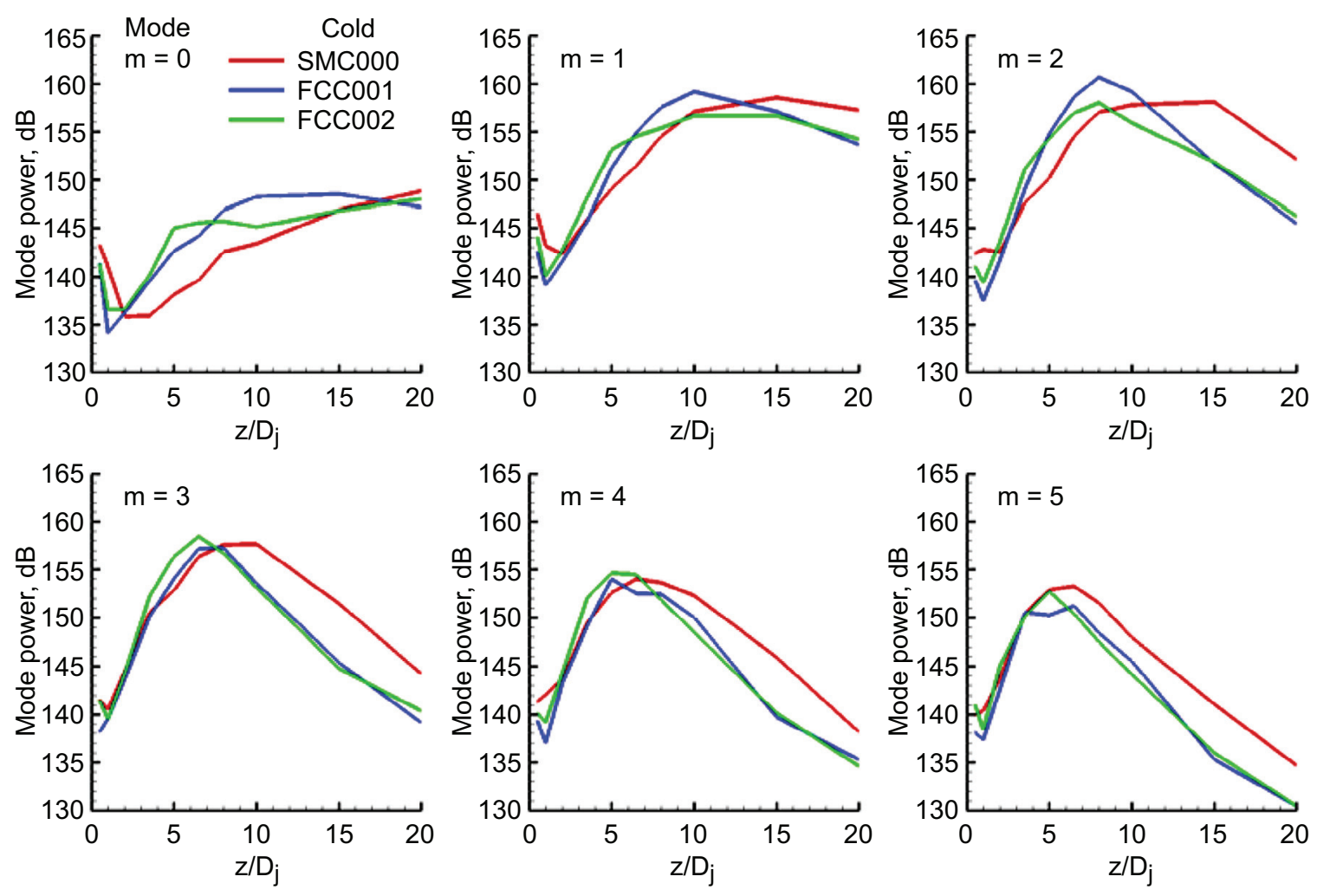

Figure 6.-Fluctuating axial velocity power $(\mathrm{dB})$ in modes 0 to 5 at the nozzle lipline radius, as a function of axial distance for the SMC000 (red), FCC001 (blue), and FCC002 (green) nozzles at a $\mathrm{M}_{\mathrm{a}}=0.9$, cold jet.
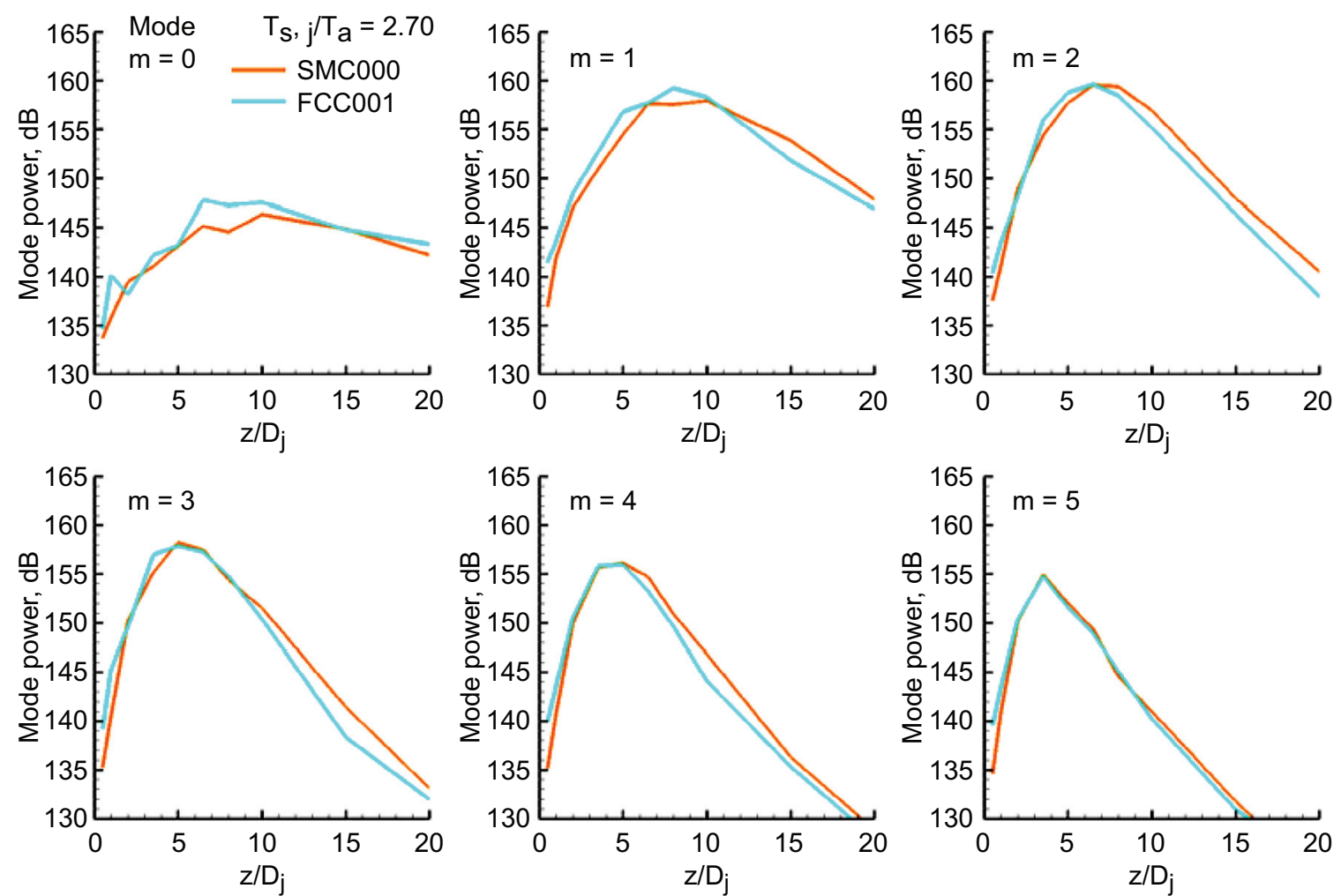

Figure 7.-Fluctuating axial velocity power $(\mathrm{dB})$ in azimuthal modes 0 to 5 at the nozzle lipline radius from the SMC000 (orange) and FCC001 (light blue) nozzles at $\mathrm{M}_{\mathrm{a}}=0.9, \mathrm{~T}_{\mathrm{S}}, \mathrm{j} / \mathrm{T}_{\mathrm{a}}=2.70$ jet. 

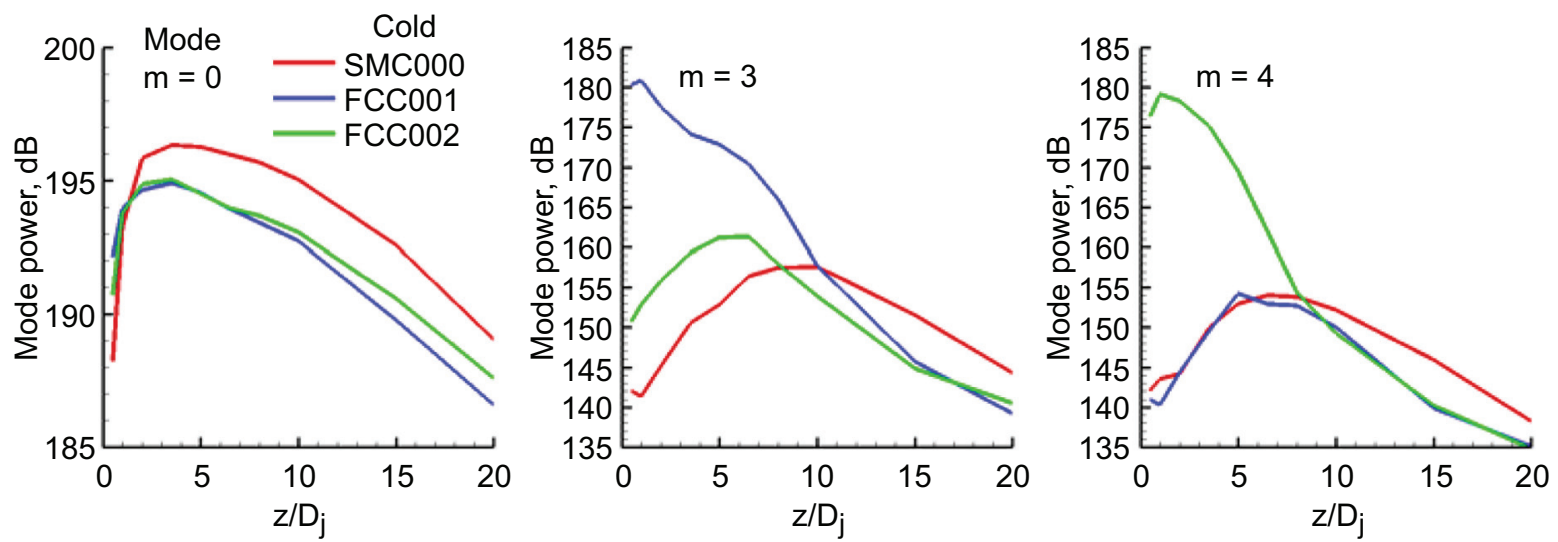

Figure 8.-Azimuthal mode power (dB) based on total axial velocity for the SMC000, FCC001, and FCC002 nozzle at $\mathrm{M}_{\mathrm{a}}=0.9$, cold jet conditions. Azimuthal modes $\mathrm{m}=0$ (left, note change in y-axis range), $\mathrm{m}=3$ (middle), and $\mathrm{m}=4$ (right) are shown. Using total axial velocity for the azimuthal mode decomposition shows the expected increase in the $m=3$ data for the 3-chevron, FCC001 nozzle and in the $\mathrm{m}=4$ data for the 4-chevron FCC002 nozzle.

cases shows each azimuthal mode peaking closer to the nozzle exit compared to the same mode from the baseline nozzle. This behavior is consistent with the increased mixing near the nozzle exit, generated by the chevrons, observed in the mean flow data. In the hot flow cases (fig. 7), shows the azimuthal modes from both the SMC000 baseline nozzle and from the FCC001 chevron nozzle peaking at approximately the same axial location. This indicates that the heat is playing the primary role in shortening the mixing region with the chevrons playing a secondary role. While these results are expected, several other observations were not predicted.

The initial concept was that chevrons add energy to the unsteady azimuthal modes in the jet plume by generating vorticies that change with time. If this idea is correct the FCC001 chevron nozzle should produce an amplified azimuthal mode $\mathrm{m}=3$ and the FCC002 chevron nozzle should produce an amplified $\mathrm{m}=4$, corresponding to the number of primary chevrons on each nozzle respectively, compared to the baseline nozzle (SMC000). While observation of the mean flow planes supports this theory, figure 6 shows that chevrons only slightly change the amplitude of these azimuthal modes computed using fluctuating axial velocity. In fact, the greatest amplification occurs at azimuthal mode $\mathrm{m}=2 \mathrm{in}$ the 3 chevron nozzle and at azimuthal mode $\mathrm{m}=3$ in the 4 chevron nozzle. This could be because these chevron nozzles use a chevron on chevron pattern that alters the azimuthal structure of the plume or because all chevrons are not generating fluctuations at the same instant leading to fewer vortices at any one time. Computing the modal decomposition using total axial velocity (fig. 8), however, shows the chevrons are generating the amplified modes initially expected. Thus, the chevrons do impart the expected azimuthal modes into the flow, but they work primarily on the mean flow component and have minimal affect on the fluctuating component. If this translates to the sound field, the azimuthal mode distribution of sound from the chevron nozzles should be similar to the baseline nozzle.

\section{Acoustic Analysis}

Previous analyses of azimuthal modes in round jets in the far field found that the lowest order modes are the most significant producers of sound (ref. 3). With the increased interest in chevron nozzles, data was analyzed to determine if this is also true for chevron nozzles, which by their nature alter the azimuthal shape of the jet. Acoustic far field and mid-field ring array data was collected from two chevron nozzles and one round baseline nozzle. While not pertaining directly to the azimuthal structure of the sound field, the far field data (fig. 9) provides the first point of consideration for the effect of the chevrons. It shows that these chevron nozzles increase noise levels at both the $90^{\circ}$ and $125^{\circ}$ angles 

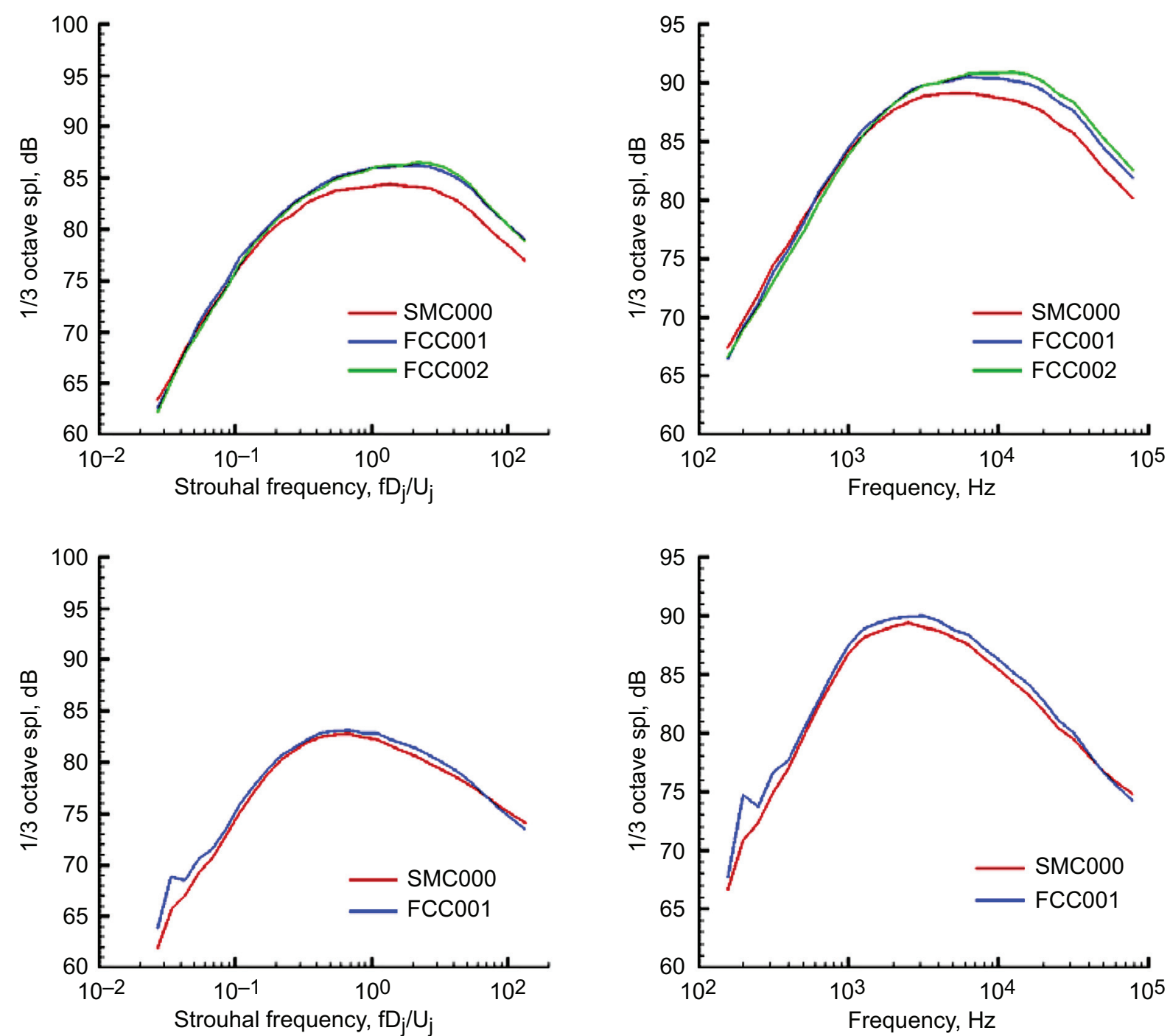

Figure 9.-Far field acoustic results for nozzles SMC000, FCC001, and FCC002 at a $\mathrm{M}_{\mathrm{a}}=0.9$, cold jet condition (top) and at $\mathrm{M}_{\mathrm{a}}=0.9, \mathrm{~T}_{\mathrm{S}}, \mathrm{j} / \mathrm{T}_{\mathrm{a}}=2.70$ jet condition (bottom) measured at $90^{\circ}$ (left) and $125^{\circ}$ (right) relative to the jet axis. Data has been transformed to a lossless condition and scaled to a distance of $100^{*} D_{j}$.

relative to the jet axis. The noise increase due to the chevrons is more in the cold jet condition compared to the hot jet condition, agreeing with the flow velocity analysis showing that chevrons are a secondary effect to heat.

The modal structure of the sound field was calculated for azimuthal mode 0 to 5 for frequencies up to approximately Strouhal frequency 1.2, the limit of the azimuthal array. The results are presented in figures 10 and 11 for nozzles SMC000, FCC001, and FCC002 at the cold, $M_{a}=0.9$ jet condition. Figure 10 shows data from the $90^{\circ}$ array location where a very gradual increase in the frequency at the peak amplitude point is observed as azimuthal mode number increases. Also at the $90^{\circ}$ array location, the lowest order azimuthal modes $(\mathrm{m}=0,1)$ have the highest peak amplitudes, around Strouhal frequency 0.3, by at least $3 \mathrm{~dB}$ but, interestingly, azimuthal mode $\mathrm{m}=2$ has the lowest peak amplitude of the modes computed for all three nozzles at the $90^{\circ}$ ring location. This is particularly of note in the FCC001 3 -chevron nozzle case where flow analysis showed the $\mathrm{m}=2$ azimuthal mode having the highest amplification further downstream. Azimuthal modes $m=4$ and $m=5$ have very similar peak amplitudes approximately $1 \mathrm{~dB}$ above the peak level in mode $\mathrm{m}=2$. The data presented at the $90^{\circ}$ ring location for 

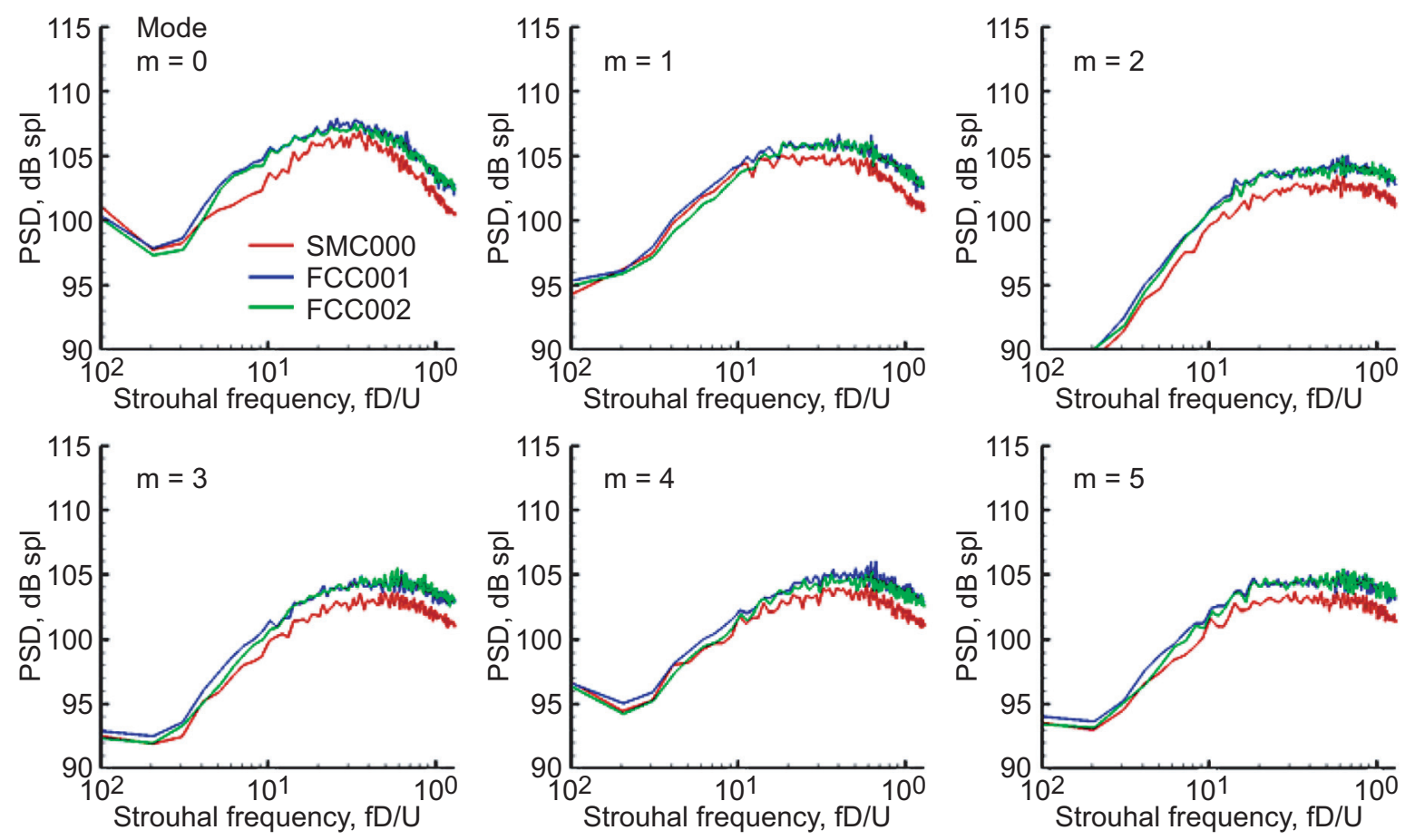

Figure 10.-Mode power spectral density at $90^{\circ}$ relative to the jet axis for nozzles SMC000, FCC001, and FCC002 at a $\mathrm{M}_{\mathrm{a}}=0.9$, cold jet condition .
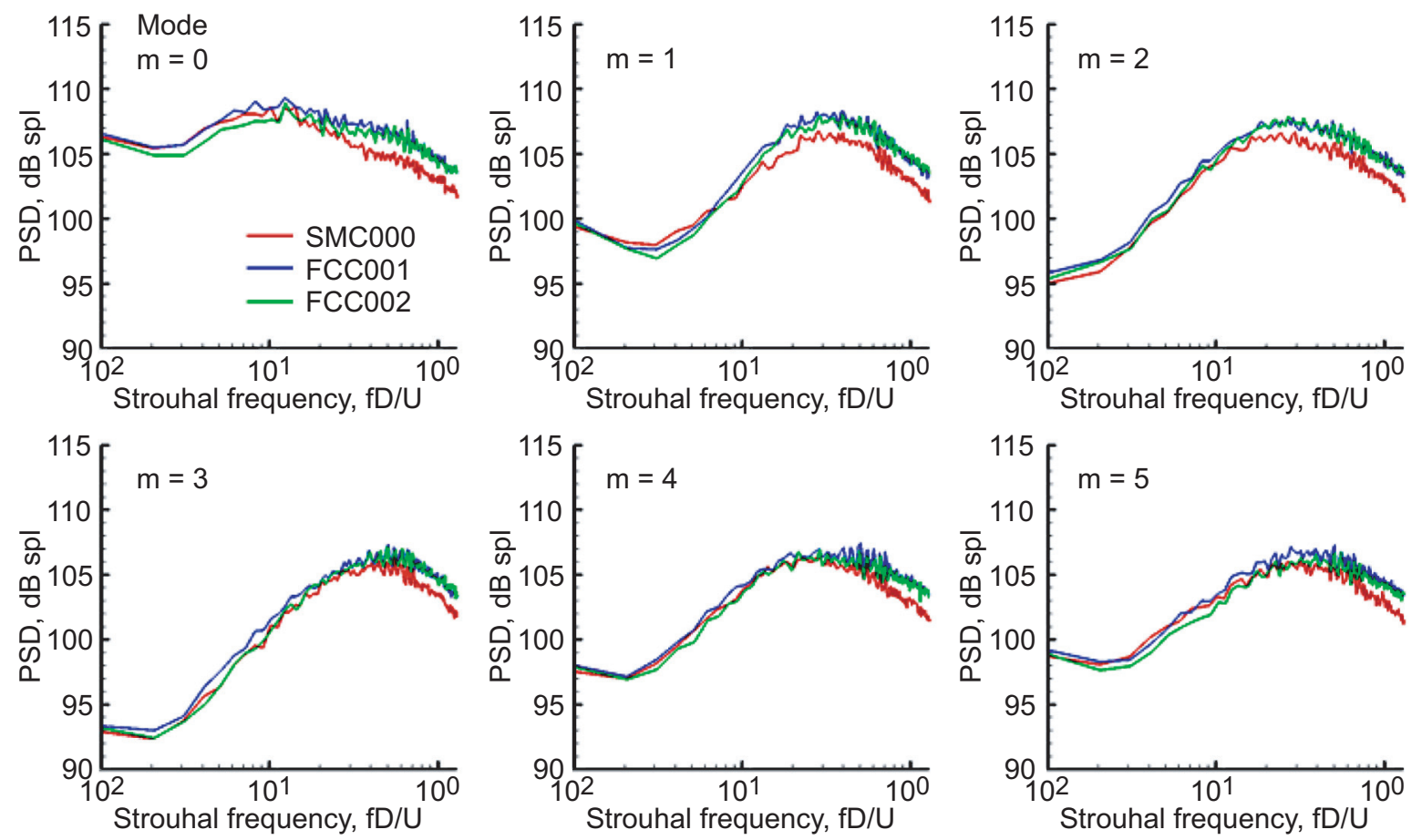

Figure 11.-Mode power spectral density at $125^{\circ}$ relative to the jet axis for the SMC000, FCC001, and FCC002 nozzles at a $M_{a}=0.9$, cold jet condition. 
all modes shows very little difference between the two chevron nozzles, both only being shifted to higher amplitudes compared to the round baseline nozzle. Data from the $125^{\circ}$ microphone ring (fig. 11) also shows the chevron nozzles having a higher peak amplitude compared to the baseline nozzle in azimuthal modes $\mathrm{m}=1,2,3$ but, unlike the $90^{\circ}$ location, similar peak amplitudes at modes $\mathrm{m}=0,4,5$. The baseline still shows reduced noise at frequencies above the peak amplitude frequency. The other significant difference between the $90^{\circ}$ and $125^{\circ}$ locations is in azimuthal mode $\mathrm{m}=2$, which is greater than modes $\mathrm{m}=3,4,5$ leaving a steady decrease in amplitude as azimuthal mode increases. Data at the $125^{\circ}$ ring location also shows little difference between the two chevron nozzles.

Data recorded for the SMC000 and FCC001 nozzles at a $M_{a}=0.9, T_{s, j} / T_{a}=2.70$ jet condition is presented in figures 12 and 13. At this jet condition, the noise difference between the chevron nozzle (FCC001) and the baseline nozzle is reduced at all modes compared to data from the cold jet condition (figs. 10 and 11). This fits with both the flow analysis and the far field acoustic results that showed the round jet better approximates the hot chevron jet than at the cold jet condition. Also of note, the reduction in azimuthal mode $\mathrm{m}=2$ observed in the cold jet at the $90^{\circ}$ location does not occur in the heated jet and azimuthal mode $m=5$ is more amplified relative to the lower order modes $m=2,3,4$. Nothing in the flow data analysis indicates why mode $\mathrm{m}=5$ should be amplified above the lower order modes. Azimuthal modes $m=0$ and $m=1$ continue to have amplitudes well above all higher modes with a Strouhal frequency at peak amplitude of $0.2(\mathrm{~m}=0)$ and $0.3(\mathrm{~m}=1)$, respectively. There is no shift in noise distribution between modes when comparing the chevron and baseline nozzles at the hot jet condition.

Data collected by Juve et al. showed only the lowest order azimuthal modes are significant in the acoustic far field of a round jet (ref. 3). Data from the round baseline nozzle analyzed during this study from the SHJAR showed a more balanced distribution of energy across the lowest 3 to 4 azimuthal
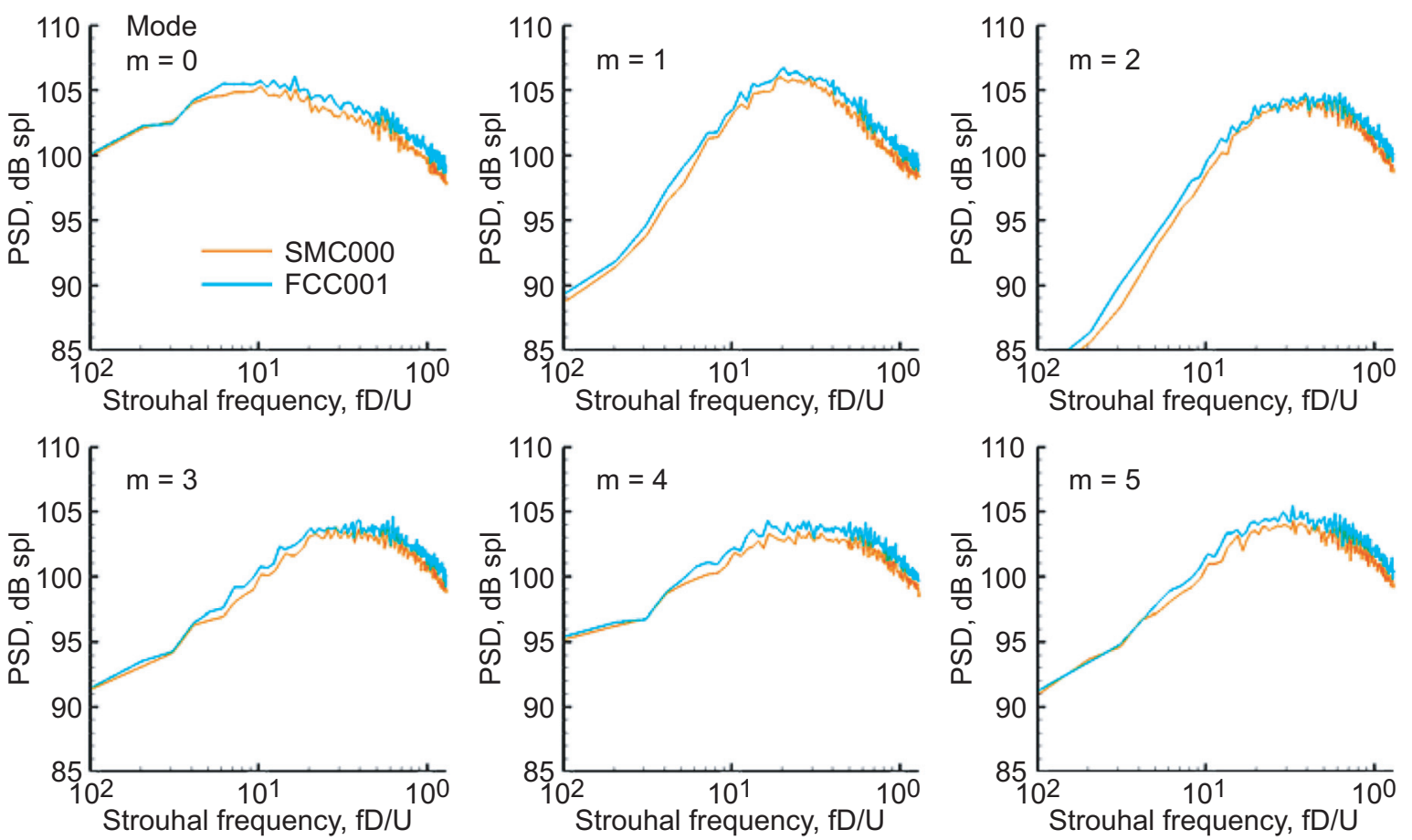

Figure 12.-Mode power spectral density for the SMC000 and FCC001 nozzles at a $\mathrm{M}_{\mathrm{a}}=0.9, \mathrm{~T}_{\mathrm{s}}, \mathrm{j} / \mathrm{T}_{\mathrm{a}}=2.70$ jet condition measured at $90^{\circ}$ relative to the jet axis. 

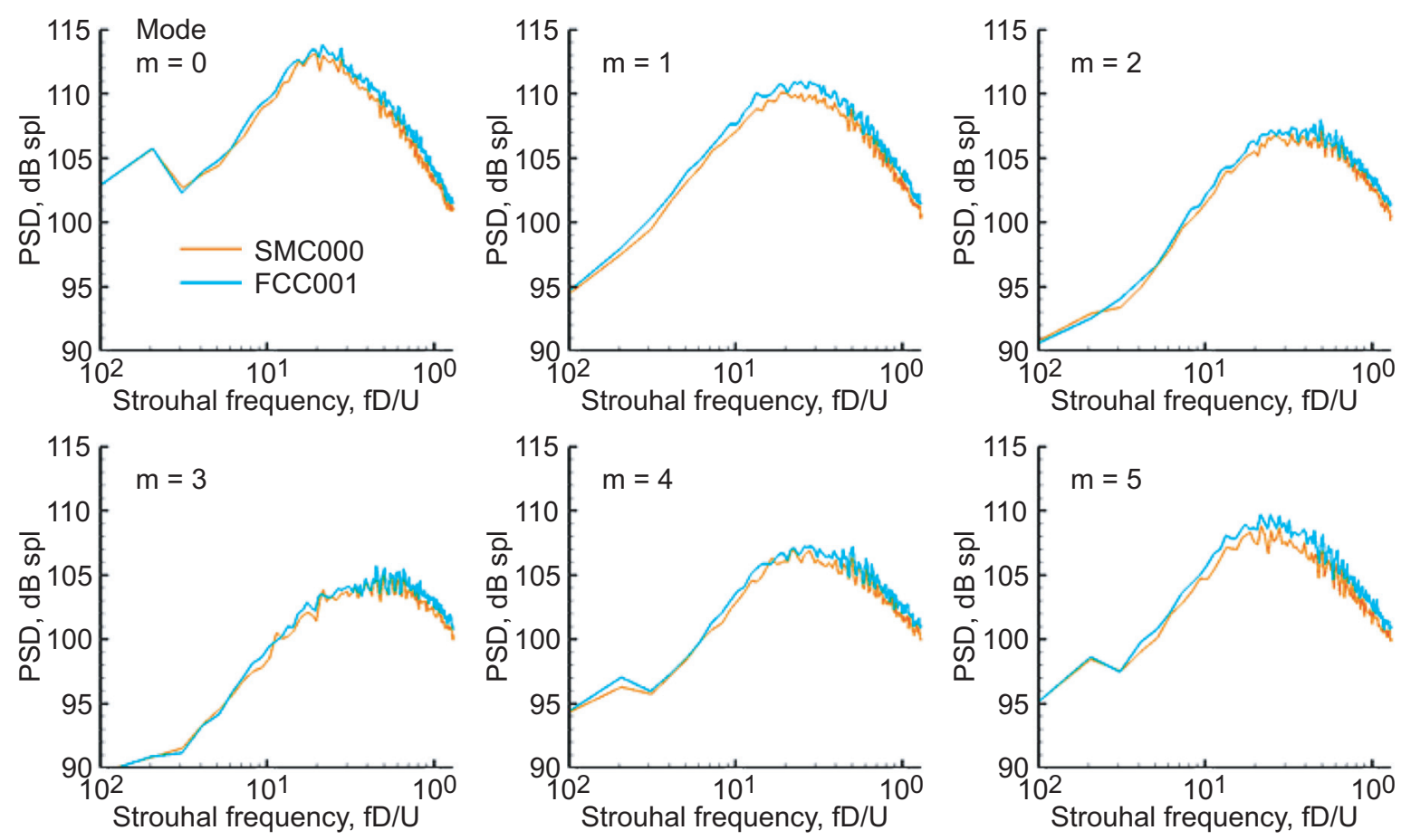

Figure 13.-Mode power spectral density for the SMC000 and FCC001 nozzles at a $\mathrm{M}_{a}=0.9, \mathrm{~T}_{\mathrm{S}}, \mathrm{j} / \mathrm{T}_{\mathrm{a}}=2.70$ jet conditions measured at $125^{\circ}$ relative to the jet axis.
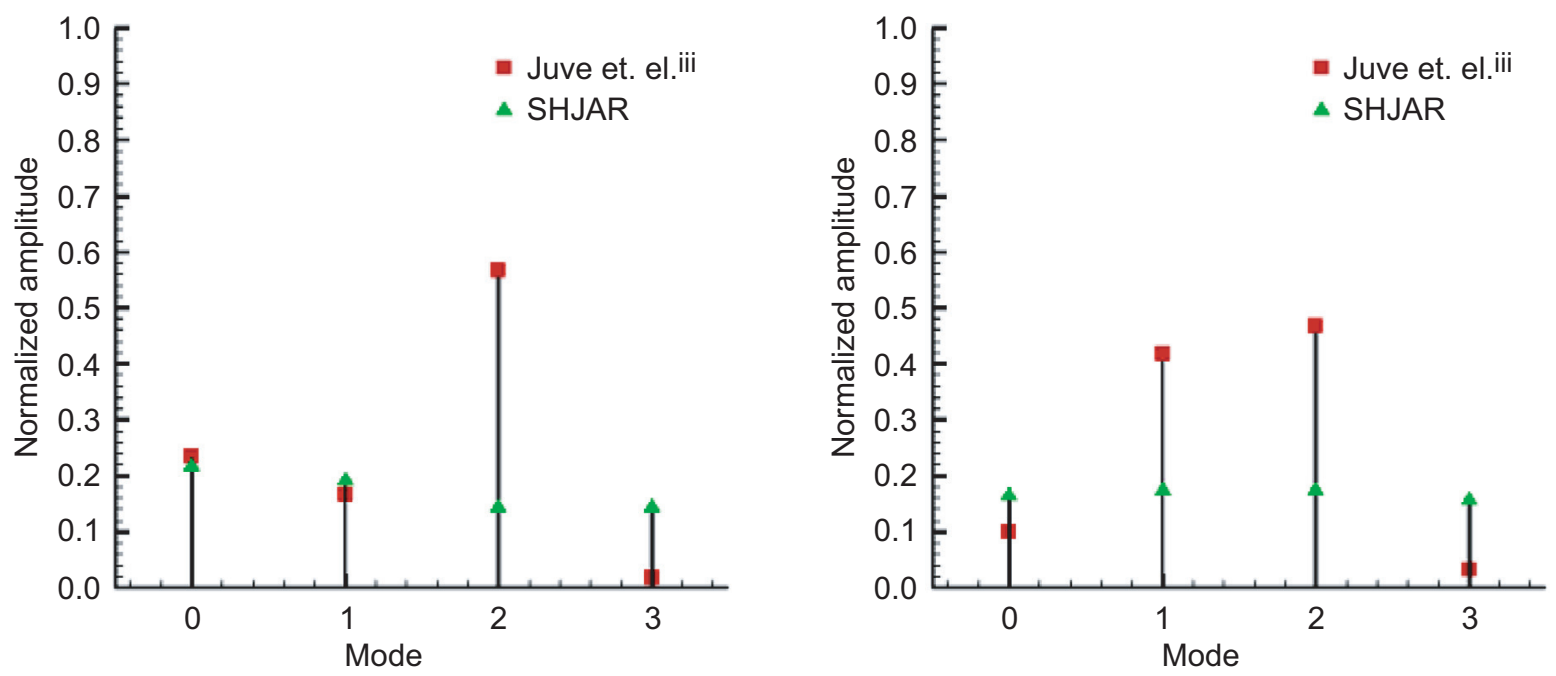

Figure 14.-Modal distribution of acoustic energy at Strouhal frequency 0.3 , measured at $90^{\circ}$ (left) and near $120^{\circ}$ (right) $\left(125^{\circ}\right.$ for the SHJAR data) relative to the jet axis, for data from Juve et. el. iii and data acquired from SHJAR.

modes. Figure 14 shows a comparison of the Juve data and the SHJAR data at Strouhal frequency 0.3 and at $90^{\circ}$ and $120^{\circ}$ relative to the jet axis $\left(125^{\circ}\right.$ in the SHJAR data). At the $90^{\circ}$ location, the data shows similar levels at azimuthal modes $\mathrm{m}=0$ and $\mathrm{m}=1$. The Juve data, however, shows significantly more energy in azimuthal mode $\mathrm{m}=2$ and almost no energy in azimuthal mode $\mathrm{m}=3$. At the $120^{\circ}$ location the Juve data has similar levels in the lowest order azimuthal mode, $\mathrm{m}=0$. The far field data of Juve then shows approximately twice the energy in azimuthal modes $\mathrm{m}=1$ and $\mathrm{m}=2$ compared to the SHJAR data but considerably less energy in mode $\mathrm{m}=3$. The SHJAR data, therefore, shows that more azimuthal 
modes may be important producers of sound compared to the Juve data. There are, however, two primary differences in the tests that should be remembered when comparing these data sets. First, the Juve data set was measured in the far field of the jet (60 to $100 D_{j}$ ) while the SHJAR data was acquired in the mid-field of the jet (approximately $20 D_{j}$ ). Second, the Juve data was recorded at a Mach 0.4 jet condition with a 2-cm nozzle diameter. The SHJAR data was acquired at a Mach 0.9 jet condition with a 2-in. nozzle diameter leading to a source that is much less compact compared to the Juve jet.

\section{Conclusions}

Theoretical and experimental studies on round nozzles, both in the near field and far field, has shown that the lowest order azimuthal modes dominate the jet. Chevron nozzles, by their very nature, change the cross-sectional shape of the jet and, therefore, should the azimuthal structure of plume turbulence. To investigate this idea, flow data previously acquired using Particle Image Velocimetry (PIV) in the crossstream plane and acoustic data acquired using a three-dimensional phased array was used to determine the modal structure of the turbulent flow and acoustic field for two chevron nozzles and one round baseline nozzle. This data set, due to the setup of the phased array, limited the scope to a maximum azimuthal mode of $\mathrm{m}=5$ and a maximum frequency of Strouhal frequency 1.2.

The PIV data was examined first to quantify the effect of chevrons on the unsteady azimuthal structure of the jet. Data from the chevron nozzles then showed that, while the cross-sectional shape does change greatly with the number and penetration of the chevrons, the change exists primarily in the mean axial flow. When the mean flow is subtracted and power in the azimuthal modes is calculated using the fluctuating axial velocity, the modal energy distribution of the chevron nozzles begins to approach that of the round baseline nozzle. In the cold jet condition, the axial location of the peak amplitude is shifted upstream toward the nozzle exit by the chevrons and some amplifications occurs, though not in the azimuthal mode corresponding to the number of chevrons, but to the azimuthal mode one less than the number of primary chevrons (i.e., nozzle with 3-primary chevrons showed maximum amplification in mode $m=2$ compared to the round jet). Data from the hot jet condition showed even smaller differences between the chevron and baseline nozzle, illustrating the strong role heat plays in the azimuthal shape of the jet.

Once the flow analysis of the flow data was complete, data from the three-dimensional phased array was used to determine modal structure of the acoustic mid-field. Far field acoustic data indicated that the chevron nozzles produced more noise than the baseline nozzle at the angle measured with the azimuthal array so some increase in amplitude compared to the baseline nozzle was expected due to the chevrons. Of particular interest, however, was the distribution of energy between the modes. Data from the cold jet showed that, although there was an offset in amplitude when comparing the chevron nozzles to the baseline, the acoustic energy was distributed in the chevron nozzles in the same way as the round nozzle. In fact, nothing observed in the sound field tied the modal spectra to the number of chevrons. Additionally, as expected based on the flow data and far field acoustic data, the hot jet condition exhibited only small amplitude differences between the chevron and baseline nozzle. Comparisons to the far field data collected by Juve et al. showed significant differences in modal distributions and significant modes in the cold, round jet compared to the SHJAR data. These differences may be due to differences in the measurement array or in the compactness of the noise source. Finally, the modal decomposition showed data in modes $m=2$ to $m=5$ have similar amplitudes and are within approximately $3 \mathrm{~dB}$ of the amplitude found in modes $\mathrm{m}=0$ or $\mathrm{m}=1$. Thus, at least the first five azimuthal modes may be important in the acoustic mid-field of a cold jet. More decrease was found in between azimuthal modes in the acoustic mid-field at the hot jet condition.

Although this study was limited by its use of existing data originally acquired for other purposes, it has provided two good observations. First, the time averaged mean flow dominates the lobed structure of the jet plume. When the time averaged mean is removed, turbulence from the chevron nozzle resembles the turbulence round nozzle in azimuthal modal structure, although the peak location of the modes moves upstream. Second, when heat is added to the jet, it plays the primary role in shaping the azimuthal 
structure of the jet (based on fluctuating axial velocity) leaving the chevrons to take a secondary place. It is important to remember that these observations are based on two chevron nozzles, only varying the number of primary chevrons on the nozzles. These observations are also only taken at two angles relative to the jet axis, $90^{\circ}$ and $125^{\circ}$, both away from the peak angle for jet noise. A more complete study using nozzles varying chevron number, length and penetration angle and a dedicated far field azimuthal array at more angles relative to the jet axis is needed to confirm these results in all cases.

\section{References}

1. Michalke, A. and Fuchs, H.V., "On turbulence and noise of an axisymmetric shear flow," J. Fluid Mech. 70(1), 179-205, 1975.

2. Armstrong, Ralph R., Michalke, Alfons, and Fuchs, Helmut V., "Coherent Structures in Jet Turbulence and Noise," AIAA J. 15(7), 1011-1017, 1977.

3. Juve, Daniel, Sunyach, Michel, and Comte-Bellot, Geneieve, "Filtered Azimuthal Correlations in the Acoustics Far Field of a Subsonic Jet," AIAA J. 17(1), 112-113, 1979.

4. Bridges, J. and Brown, C.A., "Parametric Testing of Chevrons on Single Flow Hot Jets," NASA/TM2004-213107, 2004.

5. Bridges, J. and Brown, C.A., "Validation of the Small Hot Jet Rig for Jet Noise Research," AIAA Paper 2005-2846, May 2005.

6. Brown, C. and Bridges, J., "Small Hot Jet Acoustic Rig Validation," NASA/TM-2006-214234, 2006.

7. Wernet, M.P., "Fuzzy Logic Enhanced Digital PIV Processing Software,” NASA/TM-1999-209274, 1999.

8. Opalski, Anthony B., Wernet, Mark P., and Bridges, James E., "Chevron Nozzle Performance Characterization Using Stereoscopic DPIV,” AIAA Paper 2005-444, 2005. 


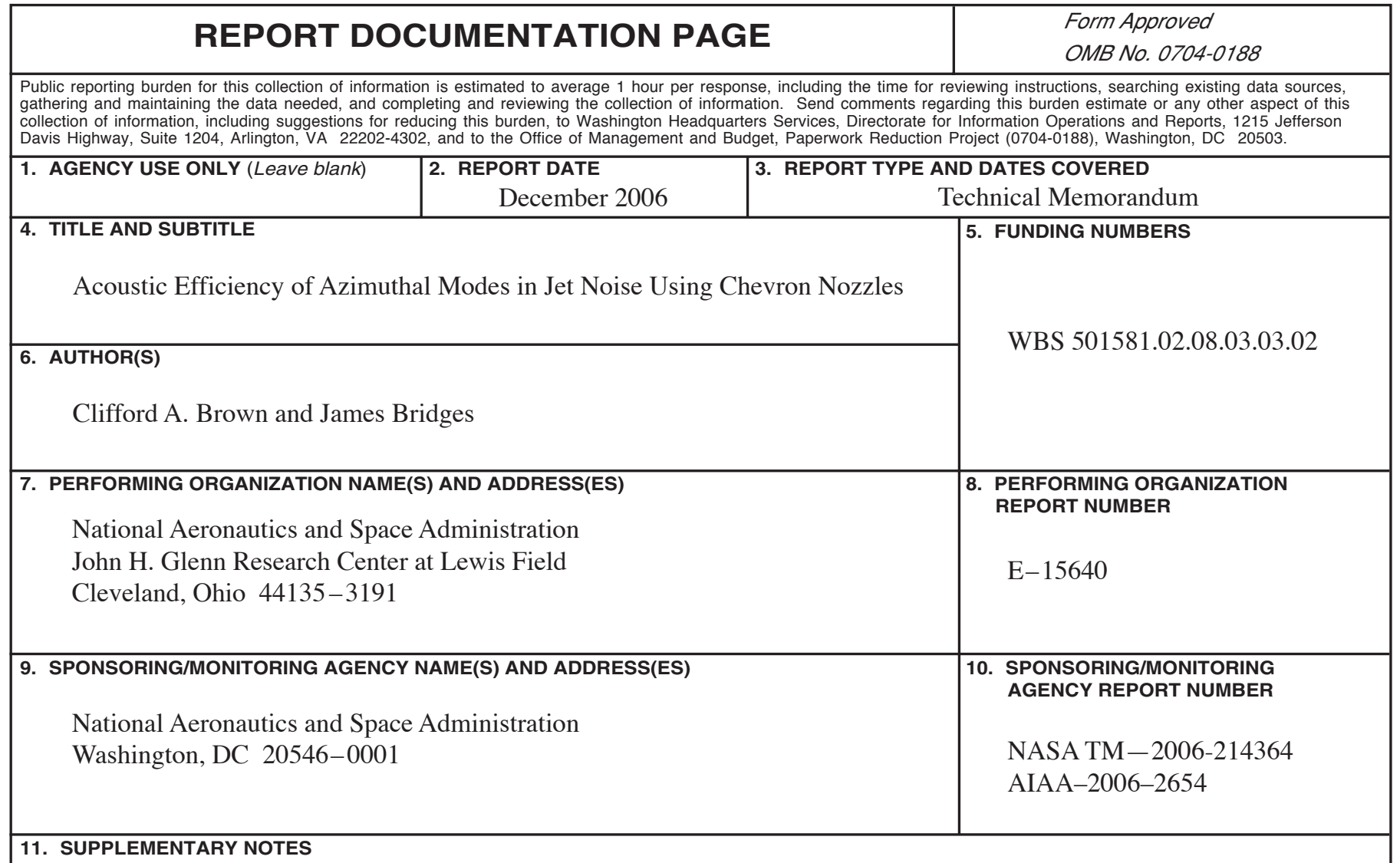

Prepared for the 12th Aeroacoustics Conference cosponsored by the American Institute of Aeronautics and Astronautics and the Confederation of European Aerospace Societies, Cambridge, Massachusetts, May 8-10, 2006. Responsible person, Clifford A. Brown, organization code RTA, 216-433-2896.

\begin{tabular}{|l|l|}
\hline 12a. DISTRIBUTION/AVAILABILITY STATEMENT & 12b. DISTRIBUTION CODE
\end{tabular}

Unclassified - Unlimited

Subject Category: 07

Available electronically at http://gltrs.grc.nasa.gov

This publication is available from the NASA Center for AeroSpace Information, 301-621-0390.

13. ABSTRACT (Maximum 200 words)

The link between azimuthal modes in jet turbulence and in the acoustic sound field has been examined in cold, round jets. Chevron nozzles, however, impart an azimuthal structure on the jet with a shape dependent on the number, length and penetration angle of the chevrons. Two particular chevron nozzles, with 3 and 4 primary chevrons respectively, and a round baseline nozzle are compared at both cold and hot jet conditions to determine how chevrons impact the modal structure of the flow and how that change relates to the sound field. The results show that, although the chevrons have a large impact on the azimuthal shape of the mean axial velocity, the impact of chevrons on the azimuthal structure of the fluctuating axial velocity is small at the cold jet condition and smaller still at the hot jet condition. This is supported by results in the azimuthal structure of the sound field, which also shows little difference in between the two chevron nozzles and the baseline nozzle in the distribution of energy across the azimuthal modes measured.

\begin{tabular}{|c|c|c|c|}
\hline \multicolumn{3}{|c|}{$\begin{array}{l}\text { 14. SUBJECT TERMS } \\
\text { Jet aircraft noise; Aeroacoustics }\end{array}$} & $\begin{array}{l}\text { 15. NUMBER OF PAGES } \\
20 \\
\text { 16. PRICE CODE } \\
\text { 20. LIMITATION OF ABSTRACT }\end{array}$ \\
\hline NSN 7540-01-280-5500 & & & $\begin{array}{l}\text { andard Form } 298 \text { (Rev. 2-89) } \\
\text { scribed by ANSI Std. Z39-18 } \\
3-102\end{array}$ \\
\hline
\end{tabular}



